\title{
Genetic diversity assessment in Indian cultivated pea (Pisum sativum L.) varieties using RAPD markers
}

\author{
Pravas Ranjan Kole ${ }^{1}$, Manoj Kumar Sharma ${ }^{2}$, Sanjay Kumar ${ }^{1}$ and Rakesh Kumar ${ }^{2}$ \\ ${ }^{1}$ National Bureau of Plant Genetic Resources, PUSA, New Delhi-110012, INDIA \\ $*^{2}$ S. V. P. University of Agriculture \& Technology, Meerut, (UP)-250110, INDIA \\ *Corresponding author. E-mail address: manojmeerut94@gmail.com \\ Received: September 15, 2014; Revised received: February 28, 2015; Accepted: April 23, 2015
}

\begin{abstract}
In the present study, the genetic diversity and inter-relationships among 12 varieties of pea were analyzed by using RAPD markers. A total of 118 bands were generated with 20 RAPD primers, of which 107 bands were polymorphic $(90.81 \%)$. The PIC value ranged from $0.602-0.863$ with an average of 0.754 . High level of polymorphism and low genetic similarity within pea varieties suggested that they have a high level of genetic diversity. Unique RAPD fragments (700bp-1500bp) were also observed in five varieties i.e., AP-01, Aparna, Uttra, Rachna and Rachna-1D. In the dendrogram, 12 varieties were broadly grouped into 2 main clusters consisting of 5 (Cluster-I) and 4 (Cluster-II) varieties, respectively, while other three varieties i.e., KPMR-522, Aparna and AP-03 were out of group. In cluster-I, Ambika and AP-01 and Rachna and Vikas showed $62 \%$ and $58 \%$ similarities whereas, HUDP-15 grouped with $56 \%$ similarities with rest two varieties. In cluster II, Uttara and Prakash showed maximum similarity (65\%) whereas, Rachna1-D showed (58\%) similarities with them. KPMR-400 showed $52 \%$ similarity in this group. KPMR-400, Aparna and AP-03 were more diverse in comparison to others. A two-dimensional plot generated from principal co-ordinate analysis of RAPD data also supported the clustering pattern of dendrogram. This study indicated the presence of high genetic diversity among pea varieties, which could be used for developing core collections of pea germplasm for breeding and germplasm management purposes.
\end{abstract}

Keywords: Genetic diversity, Pea, PCA, RAPD, UPGMA

\section{INTRODUCTION}

Pisum sativum L. $(2 \mathrm{n}=2 \mathrm{x}=14)$ the common pea (also known as the garden or field pea), is an annual herbaceous crop of the family Fabaceae or Leguminosae (Genus: Pisum, subfamily: Faboideae tribe: Fabeae), originated from the Mediterranean basin and Near East, but now widely grown for its seed pods or legumes. The term "pea" can refer to small spherical seed or to the pod. The name "peas" is also used to describe other edible seeds from the Fabaceae, such as chickpeas (Cicer arietinum), pigeon peas (Cajanus cajan), cowpeas (Vigna unguiculata), and sweet peas (several Lathyrus spp.), which are grown as ornamentals. Peas are consumed as fresh vegetables or dry seeds in most of the countries. Peas are starchy but, high in fiber, protein, vitamins (vitamin A, C, K and B complex vitamins such as folic acid, pantothenic acid, niacin, thiamine \& pyridoxine), minerals (iron, magnesium, phosphorus and zinc) and lutein (a yellow carotenoid pigment that benefits vision). The dry pea seeds are rich source of proteins (about 19-27\%) and are free of anti-nutritional substances (Petterson et al., 1997). Dry weight is about one-quarter protein and one-quarter carbohydrates, mostly sugars. In India, peas are grown as winter vegetable in plains and as summer vegetable in the hills. In India major pea producing states are Uttar Pradesh, Bihar, Haryana, Punjab, Himachal Pradesh, Orissa and Karnataka, respectively. In India, the total area and production of peas in 2010-11 was 370,000 ha and 3,517,000 metric tonnes respectively, which was the $2.4 \%$ of total vegetable production (Indian Horticulture Database, 2011). Global production in 2009 of green peas was 16 million tons, harvested from 2.1 million hectares, with an additional 10.5 million tons of dried peas, from 6.2 million hectares (FAOSTAT, 2011).

Pea cultivars have relatively narrow gene pool. Genus Pisum consist only four gene pools including fulvum, abyssinicum, arvense and sativum (Zong et al., 2009). Information about genetic diversity among pea cultivars is critical for designing optimal breeding strategies in order to obtain a continuous progress in pea improvement. The heavy use of a small number of varieties as parents by competing breeding programs have led to low genetic diversity among pea cultivars (Simioniuc et al., 2002; Baranger et al., 2004). The development of cultivated species and the breeding of new varieties have always relied on the availability of biological diversity, issuing from the long-term evolution of species. Modern plant breeding methods focusing on wide adaptation and high crop yield and intensive selection on crop species 
have raised the question of the amount of genetic variation still available in breeding pools for sustainable improvement. Determination of genetic diversity of any given crop species is a suitable precursor for improvement of the crop because it generates baseline data to guide selection of parental lines and design of a breeding scheme (Vand dar Maesen, 1990).

Molecular markers are largely used as a tool to study genetic diversity through DNA sequence variations. DNA-based or PCR-based molecular markers are most commonly used for assessing genetic diversity and other crop improvement purposes. PCR-based markers have an advantage as they require low quantities of DNA and are quick to assay. Randomly Amplified Polymorphic DNA (RAPD) technique developed by Williams et al. (1990a) is a PCR based DNA marker technology, offers advantages in speed, technical simplicity and random coverage of genome and relatively higher level of polymorphism. RAPD primers are simple arbitrary sequences of 10 nucleotides and a GC content of at least $50 \%$. When there is insufficient information about the genome sequence of a wild species, or there are economic constraints, one of the most adequate marker systems is RAPD amplification(Lima-Brito et al., 2006). RAPD markers have been used for numerous applications in plant molecular genetics research despite having disadvantages of poor reproducibility and not generally being associated with gene regions. RAPD techniques are a quick and effective method for producing species-specific fingerprints (Cipriani et al., 1996). RAPD has been extensively used for studying genetic diversity and phylogenetic relationships in several legumes including pea (Samec and Nasinec, 1995; Hoey et al., 1996; Simioniuc et al., 2002; Baranger et al., 2004; Taran et al., 2005; Yadav et al., 2010; Kwon et al., 2012).The present study was undertaken to evaluate the genetic diversity present among the pea varieties using RAPD markers.

\section{MATERIALS AND METHODS}

Plant material and DNA extraction: A total of twelve cultivated Indian pea varieties were used for the present study (Table 1). All varieties were sown in pots, containing ten seeds/pot of each variety in a complete randomized block design with three replications at National Seed Corporation (NSC), PUSA, New Delhi. On the other hand, ten seeds from each variety were put for germination in a blotting paper after treated with Thirum solution (20\%). Temperature was maintained at $20^{\circ} \mathrm{C}$ in day time and $30^{\circ} \mathrm{C}$ in night for $10-15$ days. Total genomic DNA was isolated from $0.5 \mathrm{~g}$ of germinated seeds using CTAB method (Doyle and Doyle, 1990). The quality and concentration of extracted DNA were estimated by using a UV-Vis spectrophotometer at 260/280nm using different concentrations of phage $\lambda$ DNA (Toyobo Co. Ltd., Japan) as standards. The DNA was spooled out, washed twice with $70 \%$ ethanol and incubate at room temperature overnight and finally dissolved in $80 \pm 100 \mu \mathrm{L}$ of TE [Tris-HCl $(10 \mathrm{mM}, \mathrm{pH}$ 8.0) and EDTA (1 mM, pH 8.0)] containing RNase (Ribonuclease A, $0.2 \mathrm{mg} / \mathrm{ml}$ ) and then kept at $4^{\circ} \mathrm{C}$. The DNA was then purified by phenol: chloroform extraction and ethanol precipitation, and checked for quality and purity by electrophoresis in a $0.8 \%(\mathrm{w} / \mathrm{v})$ agarose gel in 1X TAE buffer. For PCR templates, a portion of DNA was diluted up to $20 \mathrm{ng} / \mu \mathrm{L}$ and stored at $-20^{\circ} \mathrm{C}$ for further use in experiments.

Amplification of RAPD markers and data analysis: In the present study, a total of sixty three (63) random RAPD primers were evaluated for their ability to prime PCR amplification of 12 selected pea varieties. Consequently, only twenty RAPD primers which showed consistently reproducible polymorphic bands were selected and used to analyze all of the 12 pea varieties. The basic protocol reported by Williams et al. (1990b) for PCR was followed with minor modifications. For PCR amplification, each $20.0 \mu \mathrm{L}$ PCR reaction mixture consisted of $40 \mathrm{ng}$ genomic DNA, $2.0 \mu \mathrm{L}$ of 10X PCR buffer, $2.5 \mathrm{mM}$ of $\mathrm{MgCl}_{2}, 0.125 \mathrm{mM}$ dNTPs, $0.75 \mu \mathrm{M}$ for each primer and $5 \mathrm{U} / \mu \mathrm{L}$ of Taq DNA polymerase (GeNei ${ }^{\mathrm{TM}}$ Bangalore, India) and then adjusting the volume with nuclease-free water. Samples were subjected to the following thermal profiles using Bio-Gener Technology thermo cycler: initial extended step of denaturation at $94^{\circ} \mathrm{C}$ for $3 \mathrm{~min} ; 40$ cycles comprising the denaturation at $94^{\circ} \mathrm{C}$ for $1 \mathrm{~min}$, annealing at $35^{\circ} \mathrm{C}$ for $1 \mathrm{~min}$ and elongation at $72^{\circ} \mathrm{C}$ for $1 \mathrm{~min}$. An additional cycle of $5 \mathrm{~min}$ at $72^{\circ} \mathrm{C}$ was used for final extension. A $1 \mathrm{~kb}$ DNA ladder (Fermentas, Thermo Fisher Scientific, USA) was used as molecular standard in order to confirm the appropriate RAPD markers. The PCR amplified products were mixed with $2.5 \mu \mathrm{L}$ of $10 \mathrm{X}$ loading dye $(0.25 \%$ bromophenol blue, $0.25 \%$ xylene cyanol $\mathrm{FF}$ and $40 \%$ sucrose, w/v) and centrifuged briefly in a microfuge before loading. The amplified RAPD fragments were separated and visualized by electrophoresis (BIO-RAD, USA) 1.8\% (w/v) agarose gels using 1X TAE running buffer at $100 \mathrm{~V}$ for $90 \mathrm{~min}$ and detected by staining with $1.0 \mu \mathrm{g} / \mathrm{mL}$ ethidium bromide (Sigma, USA). A photographic record was taken on Gel documentation system (Syngene G Box, Biocon, India) under ultraviolet light of $260 \mathrm{~nm}$ wavelength for each PCR run. The DNA size reference standard was used for each gel. Reproducibility of the patterns was tested by running part of the reactions in duplicate. Only clear and repeatedly amplified RAPD products were scored as (1) for present bands and (0) for absent ones. The specific bands used for identifying species and cultivars were named with primer number followed by the approximate size of the amplified fragment in base pairs. All the bands were considered to avoid over/under estimation of the genetic similarity. The polymorphism information content (PIC) for each primer was calculated to estimate its allelic variation

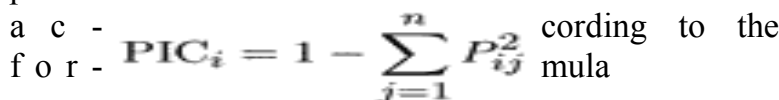


Where $P_{i j}$ is the frequency of the $i^{\text {th }}$ allele for marker $\mathrm{j}$ and the summation extends over $\mathrm{n}$ alleles, calculated for each RAPD marker (Anderson et al., 1993). In case of RAPD the PIC was considered to be $1-p^{2}-q^{2}$, where $p$ is band frequency and $q$ is no band frequency. The power of each primer to distinguish among the studied varieties was evaluated by the Resolving Power as per Prevost and Wilkinson (1999). Resolving power is the capacity of any primer to distinguish among different varieties. It is defined per primer as: $\mathrm{RP}=\Sigma \mathrm{Ib}$. Where $I b$ is the band informativeness, that takes the values of $1-[2 \times(0.5-\mathrm{P})]$, being $\mathrm{P}$ the proportion of the 12 pea varieties containing the band. Amplified products generated through RAPD primers were analysed by pair wise comparisons of the genotypes based on the percentage of common fragments, and a similarity matrix was calculated by using Jaccard similarity coefficient (Jaccard, 1908). A dendrogram was constructed based on the genetic distance matrix by applying an unweighted pair group method with arithmetic averages (UPGMA) cluster analysis version 2.0 (Kumar et al., 2001). The comparison of molecular data of all pea varieties through PCA (principal co-ordinate analysis) was also performed by using the same software.

\section{RESULTS AND DISCUSSION}

The modified CTAB protocol yielded good quality of DNA as revealed by gel electrophoresis. In the present investigation, 12 varieties of pea were fingerprinted using 63 random RAPD primers. Among the used 63
RAPD primers, 38 primers showed good amplification pattern of which, only twenty RAPD primers showing consistently reproducible polymorphic bands were selected for analysis, whereas, 25 primers did not showed satisfactory and consistently reproducible amplification. Similar observations were also reported in Mammillaria sp. (Mattagajasingh et al., 2006) and Chrysanthemum (Mukherjee et al., 2013). In their studies, Mattagajasingh et al. (2006) used 25 RAPD primers, of which 22 primers resulted in reproducible and scorable bands whereas, Mukherjee et al. (2013) reported that 16 primers out of 20 RAPD primers resulted in the amplification of distinct and reproducible bands. The features of the primers tested across all 12 pea varieties are summarized in table 2. RAPD markers yielded a total number of 118 bands, of which 107 bands were found to be polymorphic and only 11 bands were monomorphic. These amplified bands ranged from $280 \mathrm{bp}$ to $2400 \mathrm{bp}$. The number of amplified bands/primer ranged from 4-9, with an average of 5.9 while the number of polymorphic bands/primer ranged from 4-8, with an average of 5.35 (Table 2). The highest number of alleles was observed for the primers OPC-5, OPC-11 and OPC-15 (8 alleles) followed by OPC-18 and OPO-11 (7 alleles), OPB-17, OPC-7, OPC-19 and OPN-6 (6 alleles), OPB-10, OPB-18 and OPC-8 (5 alleles each), OPB-11, OPC-1, OPC-2, OPO-16, OPO-20 and OPC-9 (4 alleles each), whereas; OPB-12 and OPO-15 (3 alleles each) showed the lowest number of alleles (Table 2). Polymorphic Information Content values vary from 0.602 (for primer OPB-11) to 0.863 (for primer OPC-15) with an average of 0.754 (Table

Table 1. Details of twelve pea varieties used in the present study.

\begin{tabular}{|c|c|c|c|}
\hline S. N. & Variety name & Parentage & Recommended states for cultivation \\
\hline 1 & AMBIKA (IM-9102) & DMR $22 \times$ HUP 7 & Maharashtra, Madhya Pradesh, Uttar Pradesh \\
\hline 2 & KPMR 400 (INDRA) & Rachna $\times$ HFP 4 & $\begin{array}{l}\text { Madhya Pradesh, Maharashtra, Chhattisgarh, } \\
\text { Gujarat, Budelkhand region of Uttar Pradesh }\end{array}$ \\
\hline 3 & KPMR-522 (JAY) & KPMR $156 \times$ HFP 4 & Punjab, Haryana, U. P., Rajasthan \& Delhi \\
\hline 4 & Vikas (IPFD 99-13) & HFP $4 \times$ LFP 80 & $\begin{array}{l}\text { Chhattisgarh, Gujarat, Himachal Pradesh, } \\
\text { M. P. Maharashtra, Bundelkhand region of U. P. }\end{array}$ \\
\hline 5 & Prakash (IPFD 1-10) & PDPD $8 \times$ HUDP 7 & $\begin{array}{l}\text { U. P., Chhattisgarh, Assam, M. P., J \& K, } \\
\text { Gujarat, Maharashtra, Bundelkhand region of U.P., } \\
\text { Uttarakhand, Himachal Pradesh \& Hilly regions of } \\
\text { NEH states }\end{array}$ \\
\hline 6 & APARNA & Type $163 \times$ EC109196 & Commercially cultivated in Orissa \\
\hline 7 & Rachna-1D & --- & --- \\
\hline 8 & Rachna & Type-163 $\times$ Type-10 & $\begin{array}{l}\text { U. P., M. P., Haryana, Bihar, Chhattisgarh, } \\
\text { Himachal Pradesh, J \& K, Assam \& Orissa }\end{array}$ \\
\hline 9 & $\begin{array}{l}\text { HUDP-15 (Malviya } \\
\text { Matar-15) }\end{array}$ & $(\mathrm{PG} 3 \times \mathrm{S} 143) \times \mathrm{FC} 1$ & $\begin{array}{l}\text { J \& K, Himachal Pradesh, U. P., Assam, Bihar, } \\
\text { Orissa, West Bengal \& Neh region }\end{array}$ \\
\hline 10 & UTTARA (HFP-8909) & EC- $109185 \times$ HFP-4 & Delhi, Haryana, Rajasthan, Uttar Pradesh \\
\hline 11 & AZAD (AP-1) & $6416 \times 6405$ & Uttar Pradesh, Uttaranchal, Sikkim \\
\hline 12 & AZAD (AP-3) & -- & Uttar Pradesh, Uttaranchal, Sikkim \\
\hline
\end{tabular}


Table 2. Different properties of RAPD primers used for the present study.

\begin{tabular}{|c|c|c|c|c|c|c|c|c|c|}
\hline $\begin{array}{l}\text { S. } \\
\text { No }\end{array}$ & $\begin{array}{l}\text { Primer } \\
\text { Name }\end{array}$ & $\begin{array}{l}\text { Primer Sequence } \\
\qquad\left(5^{\prime} \rightarrow 3^{\prime}\right)\end{array}$ & NAB & NPB & PPB \% & $\mathbf{R P}$ & DI & PIC & HE \\
\hline 1 & OPB-10 & CTGCTGGGAC & 5 & 5 & 100 & 2.000 & 0.833 & 0.755 & 0.789 \\
\hline 2 & OPB-11 & GTAGACCCGT & 4 & 4 & 100 & 2.000 & 0.837 & 0.602 & 0.665 \\
\hline 3 & OPB-12 & CCTTGACGCA & 5 & 3 & 60 & 1.333 & 0.569 & 0.618 & 0.675 \\
\hline 4 & OPB-17 & AGGGAACGAG & 6 & 6 & 100 & 2.500 & 0.645 & 0.795 & 0.821 \\
\hline 5 & OPB-18 & CCACAGCAGT & 5 & 5 & 100 & 2.500 & 0.929 & 0.765 & 0.798 \\
\hline 6 & OPC-1 & TTCGAGCCAG & 4 & 4 & 100 & 2.000 & 0.910 & 0.685 & 0.735 \\
\hline 7 & OPC-2 & GTGAGGCGTC & 4 & 4 & 100 & 1.833 & 0.394 & 0.660 & 0.713 \\
\hline 8 & OPC-5 & GATGACCGCC & 8 & 8 & 100 & 3.833 & 0.796 & 0.840 & 0.856 \\
\hline 9 & OPC-7 & GTCCCGACGA & 7 & 6 & 85.7 & 1.667 & 0.764 & 0.822 & 0.842 \\
\hline 10 & OPC-8 & TGGACCGGTG & 6 & 5 & 83.7 & 1.833 & 0.622 & 0.691 & 0.731 \\
\hline 11 & OPC-9 & TGGACCGGTG & 4 & 4 & 100 & 1.000 & 0.456 & 0.632 & 0.685 \\
\hline 12 & OPC-11 & AAAGCTGCGG & 8 & 8 & 100 & 4.333 & 0.852 & 0.783 & 0.809 \\
\hline 13 & OPC-15 & GACGGATCAG & 9 & 8 & 88.8 & 3.667 & 0.441 & 0.863 & 0.876 \\
\hline 14 & OPC-18 & TGAGTGGGTG & 7 & 7 & 100 & 1.833 & 0.981 & 0.817 & 0.837 \\
\hline 15 & OPC-19 & GTTGCCAGCC & 7 & 6 & 85.7 & 2.833 & 0.354 & 0.825 & 0.844 \\
\hline 16 & OPN-6 & GAGACGCACA & 7 & 6 & 85.7 & 2.667 & 0.516 & 0.806 & 0.828 \\
\hline 17 & OPO-11 & GACAGGAGGT & 7 & 7 & 100 & 2.500 & 0.923 & 0.854 & 0.868 \\
\hline 18 & OPO-15 & TGGCGTCCTT & 5 & 3 & 60 & 2.333 & 0.661 & 0.763 & 0.795 \\
\hline 19 & OPO-16 & TCGGCGGTTC & 6 & 4 & 66.6 & 2.667 & 0.692 & 0.799 & 0.824 \\
\hline \multirow[t]{2}{*}{20} & OPO-20 & ACACACGCTG & 4 & 4 & 100 & 2.500 & 0.734 & 0.702 & 0.749 \\
\hline & & $\begin{array}{l}\text { Total } \\
\text { Average }\end{array}$ & $\begin{array}{l}118 \\
5.9\end{array}$ & $\begin{array}{r}107 \\
5.35\end{array}$ & 90.81 & $\begin{array}{c}47.832 \\
2.392\end{array}$ & $\begin{array}{c}13.909 \\
0.695\end{array}$ & $\begin{array}{c}15.077 \\
0.754\end{array}$ & $\begin{array}{c}15.739 \\
0.787\end{array}$ \\
\hline
\end{tabular}

Here, $\mathrm{NAB}=$ Number of amplified bands, NPB $=$ Number of polymorphic bands, $\mathrm{PPB} \%=$ Percentage of polymorphic bands, $\mathrm{RP}=$ Resolving power, $\mathrm{DI}=$ Diversity index, $\mathrm{PIC}=$ Polymorphic information content, $\mathrm{HE}=$ Heterozygosity

Table 3. Five unique PCR bands amplified in pea varieties with different RAPD primers.

\begin{tabular}{llcc}
\hline S. N. & Variety name & Primer revealing unique RAPDs & Fragment size (in bp) \\
\hline 1 & AP-01 & OPN6 & 700 \\
2 & Aparna & OPN11 & 600 \\
3 & Uttra & OPN11 & 280 \\
4 & Rachna & OPB11 & 1200 \\
\hline
\end{tabular}

2). RAPD Primer OPC-15 was the most informative primer, with the highest PIC of 0.863 , whereas, the primer OPB-11 showed the lowest PIC value of 0.602 (Table 2). These 20 highly polymorphic primers produced an average PIC of 0.754 (Table 2).

Maximum number of amplified products was nine (for primer OPC-15) while minimum was four (for primers OPB-11, OPC-1, OPC-2, OPC-9 and OPO-20). Polymorphism level was maximum (100\%) for primers OPB-10, OPB -11, OPB-17, OPB-18, OPC-1, OPC-2, OPC-5, OPC-9, OPC-11, OPC-15, OPC-18, OPO-20 and OPO-11 and minimum (60\%) for primer OPB-12 and OPO-15 with an average of $90.81 \%$. The polymorphic information content (PIC), measured as the percentage of polymorphic fragments for all primer pairs was high and varied in a relatively narrow range of $60.2 \%$ (for primer OPB-11) to $86.3 \%$ (for primer OPC-15), with an average of $75.4 \%$ (Table 2). The resolving power (RP) varied between 1.000 (for primer OPC-9) and 4.333 (for primer OPC-11) with an average value of 2.392 (Table 2 ). The results indicated the presence of high degree of polymorphism in pea varieties and this makes them distinguishable on the basis of banding pattern. The RAPD profiles of all the primers that generated sharp, intense and easily scorable polymorphic bands were surveyed to obtain a set of a minimum number of primers that could distinguish all the 12 varieties from each other. In earlier studies, it has been observed that 
Table 4. Jaccard's similarity coefficient of the 12 pea varieties based on 20 polymorphic RAPD markers.

\begin{tabular}{|c|c|c|c|c|c|c|c|c|c|c|c|c|}
\hline & Ambika & $\begin{array}{c}\text { Rachna } \\
\text { 1D }\end{array}$ & Rachna & Vikas & Uttara & $\begin{array}{l}\text { HUDP } \\
15\end{array}$ & $\begin{array}{l}\text { KPMR } \\
522 \\
\end{array}$ & Prakash & AP 01 & AP 03 & $\begin{array}{l}\text { KPMR } \\
400 \\
\end{array}$ & Aparna \\
\hline \multicolumn{13}{|l|}{ Ambika } \\
\hline Rachna 1D & 0.53 & & & & & & & & & & & \\
\hline Rachna & 0.53 & 0.53 & & & & & & & & & & \\
\hline Vikas & 0.55 & 0.49 & 0.57 & & & & & & & & & \\
\hline Uttra & 0.57 & 0.57 & 0.54 & 0.60 & & & & & & & & \\
\hline HUDP 15 & 0.58 & 0.41 & 0.57 & 0.54 & 0.50 & & & & & & & \\
\hline KPMR 522 & 0.41 & 0.32 & 0.50 & 0.41 & 0.40 & 0.41 & & & & & & \\
\hline Prakash & 0.55 & 0.57 & 0.45 & 0.54 & 0.65 & 0.41 & 0.45 & & & & & \\
\hline AP 01 & 0.65 & 0.47 & 0.52 & 0.61 & 0.51 & 0.46 & 0.50 & 0.57 & & & & \\
\hline AP 03 & 0.30 & 0.24 & 0.32 & 0.23 & 0.21 & 0.23 & 0.39 & 0.33 & 0.33 & & & \\
\hline KPMR 400 & 0.52 & 0.49 & 0.44 & 0.42 & 0.57 & 0.54 & 0.36 & 0.51 & 0.41 & 0.31 & & \\
\hline Aparna & 0.46 & 0.35 & 0.32 & 0.31 & 0.35 & 0.39 & 0.28 & 0.35 & 0.36 & 0.17 & 0.44 & \\
\hline Max. & 0.65 & 0.57 & 0.57 & 0.61 & 0.65 & 0.54 & 0.50 & 0.57 & 0.41 & 0.31 & 0.44 & 0.65 \\
\hline Min. & 0.30 & 0.24 & 0.32 & 0.23 & 0.21 & 0.23 & 0.28 & 0.33 & 0.33 & 0.17 & 0.44 & 0.17 \\
\hline
\end{tabular}

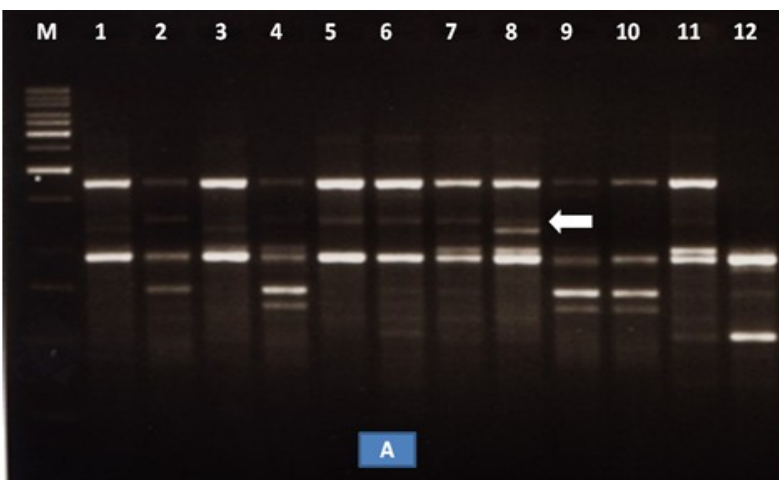

RAPD primer profiling of 12 pea varletles using OPB-11 primer, Here, 1 AMBAKA, 2 - KPMR 400, 3 - KPMR 522, 4 - Vikas, 5 - Prakash, 6 - APARNA, 7 Rachna 1D, 8 - Rachina, 9 - HUDP 15, 10 - UTTRA, 11 - AP 01, 12 - AP 03 , 1kb DilA Ladder (M) was used.

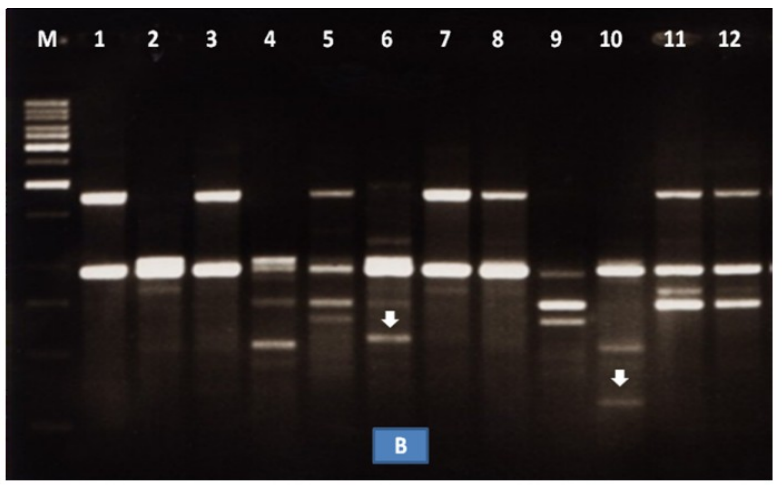

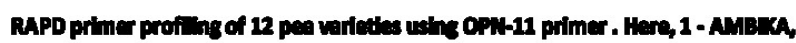
2 - IPMR 400, 3 - IPMR 523, 4 - Vikes, 5 - Preksoh, 6 - APARUA, 7 - Rachno 1D, 8 Rachna, 9- HUDP 15, 10 - UTTM, 11 - AP 01, 12 - AP 03 . 1\%b DirA Laddor (M) wres used

Fig. 1. RAPD primer profiles of 12 pea varieties using (A) OPB-11 primer (B) OPN-11 primer. Here, lane 1-AMBIKA; 2-KPMR 400; 3-KPMR 522; 4-Vikas; 5-Prakash; 6-APARNA; 7-Rachana 1D; 8-Rachana; 9-HUDP 15; 10-UTTRA; 11-AP 01; $12-A P 03$. $M=1 \mathrm{~kb}$ DNA ladder used. White arrows are showing unique bands.

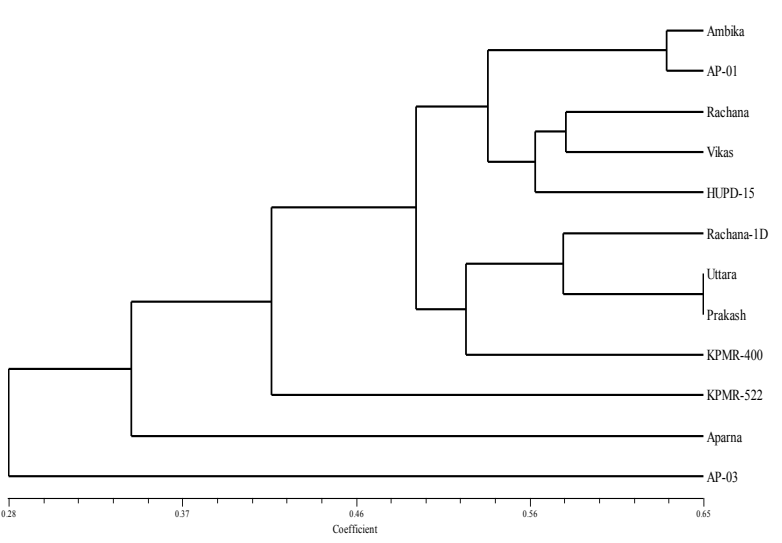

Fig. 2. UPGMA dendrogram showing relationships among 12 pea varieties based on RAPD analysis.

a set of small number of RAPD primers were sufficient enough to successfully identify and distinguish different plant varieties (Samec and Našinec, 1996; Lema-Ruminska et al., 2004; Ahmad et al., 2010; Yadav et al., 2010). This pattern was also reflected in the respective phylogenetic trees and similarity values between two varieties. To know the proper genetic background of parents or different

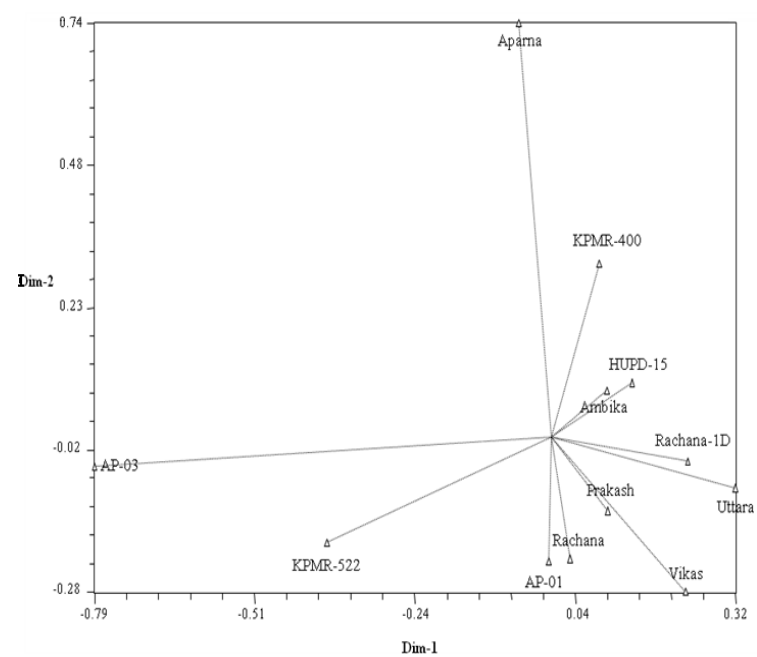

Fig. 3. Two dimensional PCA (Principle Co-ordinate Analysis) scaling of twelve varieties of pea using RAPD markers.

varieties of plant material, genetic diversity present at the molecular level as reflected by the polymorphic DNA sequence can be used. In the present study, high level of polymorphism $(90.81 \%)$ was observed among 
pea varieties. Our results also revealed that the marker technique used was capable of detecting genetic variations in pea varieties. The polymorphism rate observed in this study was much higher than that generated using RAPD markers in pea (Choudhury et al., 2007; Samatadze et al., 2008; Ahmad et al., 2010; Yadav et al., 2010; Kwon et al., 2012) and other plant species like- safflower (Mahasi et al., 2009). The variation of polymorphism rate reflects extend of the genetic divergence among and within the populations studied and RAPD markers used. These findings demonstrate the usefulness of RAPD markers in detecting genetic variability in various plant species. The precision and accuracy in detecting genetic diversity at a molecular level makes it the marker system of the choice when studying closely related genotypes. Gel images obtained from the RAPD banding profile of primers OPB-11 and OPN-11 are shown in fig. 1, which exemplifies the typical banding patterns.

A search for unique bands was also made for five varieties with four RAPD primers, however these primers generated unique bands in varieties can be used for developing core collections of pea germplasm for breeding and germplasm management purposes. In such a way among the polymorphic RAPDs those present only in one variety were considered to be unique fragments (Table 3; Fig. 1). For five varieties out of 12, it was possible to find at least one such fragment. The size of unique RAPD fragments ranged 700bp-1500bp. Unique DNA fragments were also obtained in some Indian scented rice varieties by using RAPD primers (Raghunathachari et al., 2000). All the 109 bands, generated from 20 RAPD primers, were subjected to calculate the genetic Jaccard's similarity index (RAPD-GS) among the 12 pea varieties (Table 4). The genetic coefficients measured from molecular data on 20 polymorphic RAPD markers revealed varying degrees of genetic relatedness among the pea varieties. The Jaccard similarity index of pair-wise comparisons estimated on the basis of all the 20 primers ranged from 0.17 to 0.65 , indicating that a high level of genetic diversity existed among the 12 pea varieties.

Pea varieties Uttara and Prakash and Ambika and AP 01 revealed the maximum similarity of 0.65 , followed by Vikas and AP $01(0.61)$, Vikas and Uttra (0.60), Ambika and HUPD 15 (0.58) and Ambika and Uttra, Rachna 1D and Uttra, Rachna 1D and Prakash, Rachna and Vikas, Rachna and HUPD 15, Uttara and KPMR 400 and Prakash and AP 01 (0.57). Varieties AP 03 and Aparna showed the least genetic similarity of 0.17 , followed by Uttara and AP 03 (0.21), 0.23 between Vikas, AP 03 and HUDP15, Rachna 1D and AP 03 (0.24) and 0.33 between Prakash, AP 01 and AP 03 (Table 4). According to the GS value, AP 03 and Aparna appear as the most dissimilar and distantly related varieties whereas; Ambika and AP 01 and Uttara and Prakash were closely related with each other. Very wide range of genetic similarity (0.0-1.0) between pea cultivars was also reported by many workers using protein and PCR-based markers (Samec and Našinec, 1996; Simioniuc et al., 2002; Baranger et al., 2004). The higher estimated genetic distance could be ascribed to differences between accessions owing to diversification in the pedigree of the genotypes. The input matrix for genetic analysis among the 12 pea varieties were prepared from the scoring of main alleles obtained. A dendrogram is generated by UPGMA to show the genetic relationships among the pea varieties studied. The cluster analysis based on UPGMA with 20 RAPD primers allowed the discrimination of varieties and provided a clear resolution of relationships among all them.

The relationships between the 12 pea varieties revealed by cluster analyses and PCA based on UPGMA are presented in figs. 2, 3 respectively. In the dendrogram, 12 varieties were broadly grouped into 2 main clusters consisting of 5 (Cluster-I) and 4 (Cluster-II) varieties, respectively, while other three varieties i.e., KPMR-522, Aparna and AP-03 were out of group (Fig. 2). Cluster I consisted of five varieties i.e., Ambika, AP-01, Rachna, Vikas and HUPD-15 while Cluster II consisted of four varieties i.e., Rachna-1D, Uttara, Prakash and KPMR-400, respectively. Cluster I is further divided into two sub-groups called subgroup-I and subgroup-II. Sub-group I consists two varieties i.e., Ambika and AP-01, they showed $62 \%$ similarity between them. Sub-group II consist three varieties named as Rachana, Vikas and HUPD-15. In this subgroup, Rachna and Vikas showed 58\% similarities between them. HUPD-15 grouped with 56\% similarities with rest two varieties. In cluster II, Uttara and Prakash showed maximum similarity (65\%) while, Rachna1-D showed (58\%) similarities with them. KPMR-400 shows $52 \%$ similarity in this group. KPMR-400, Aparna and AP-03 were more diverse in comparison to others. These varieties can be further used in crop improvement programmes. According to the similarity index variety Uttara showed highest similarity with Prakash (0.65) while AP-03 was the most diverse among all 12 varieties. To obtain an alternative view of the relationship between the varieties Principal co-ordinate Analysis was done with combined data (Fig. 3). Principal co-ordinate analysis (PCA) is one of the multiple approaches of forming groups based on the similarity coefficients or varience-covarience among the traits of entries (Akond et al., 2007; Mukherjee et al., 2013).

In the present study, the cluster analysis and PCA analysis for RAPD marker system showed clear grouping pattern and the results obtained through PCA were slightly differing from UPGMA cluster analysis. The two-dimensional co-ordination confirms the cluster analysis results showing that the varieties KPMR-400, Aparna, KPMR-522 and AP-03 were separated (Fig. 3). The coherence of dendrogram and PCA strongly support the reliability of the marker system. Two-dimensional (2-D; Fig. 3) plots were 
prepared using the 2 PCs. The distribution of all twelve varieties on the PCA plot as in the dendrogram also suggested distinct differentiation among the different groups (Fig. 3). In the present study, high level of genetic variability among the studied pea varieties was also reflected in PCA analysis using RAPD markers. Mukherjee et al. (2013) also reported similar results while studying the genetic diversity in Chrysanthemum varieties using RAPD and ISSR markers.

\section{Conclusion}

The present study revealed that the levels of genetic differentiation among the twelve varieties of pea increased with geographical distance. The polymorphism detected among the varieties will be helpful in selecting genetically diverse cultivars in future breeding programmes. However, there were some precincts in the present study that only twelve varieties and twenty primers were used in RAPD analysis and hence reduced the chance to obtain a reliable knowledge precisely about the genetic structure of each pea variety. Further studies would be conducted by using more number of varieties and advanced molecular markers in order to trap maximum genetic diversity within this species. Results derived from this study can be used in germplasm management practices, developing core collections and as guidance to breeders for planning future explorations, collections and other crop improvement purposes.

\section{ACKNOWLEDGEMENT}

The authors are grateful to National Seed Corporation (NSC), New Delhi for providing seed samples used in the present study.

\section{REFERENCES}

Ahmad, G., Mudasir., Kudesia, R., Shikha and Srivastava, M.K. (2010). Evaluation of genetic diversity in Pea (Pisum sativum L) using RAPD analysis. Genetic Engineering \& Biotechnology Journal, 16: 1-5.

Akond, M.A., Watanabe, N. and Furuta, Y. (2007). Exploration of genetic diversity among Xinjiang Triticum and Triticum ponicum by AFLP markers. Journal of Applied Genetics, 48: 25-33.

Anderson, J.A., Churchill, G.A., Autrique, J.E., Tanksley, S.D. and Sorrells, M.E. (1993). Optimizing parental selection for genetic linkage maps. Genome, 36: 181-186.

Baranger, A., Aubert, G., Arnau, G., Laine, A.L., Deniot, G., Potier, J., Weinachter, C., Lejeune-Hénaut, I., Lallemand, J. and Burstin, J. (2004). Genetic diversity within Pisum sativum using protein and PCR-based markers. Theoretical and Applied Genetics, 108 (7): 1309-1321.

Choudhury, P.R., Tanveer, H. and Dixit, G.P. (2007). Identification and detection of genetic relatedness among important varieties of pea (Pisum sativum L.) grown in India. Genetica, 130: 183-191.

Cipriani, G., Bella, R. and Testolin, R. (1996). Screening of RAPD primers for molecular taxonomy and cultivar fingerprinting in genus Actinidia. Euphytica, 90: 169-174.

Doyle, J.J. and Doyle, J.L. (1990). Isolation of plant DNA from fresh tissues. Focus, 12: 13-15.
FAOSTAT (2011). Online statistics database of the Food and Agriculture Organization of the United Nations, Statistics on dry peas and green peas, retrieved 3 November 2011 from http://faostat.fao.org/site/291/ default. aspx.

Hoey, B.K., Crowe, K.R., Jones, V.M. and Polans, M.O. (1996). A phylogenetic analysis of Pisum based on morphological characters, allozyme and RAPD markers. Theoretical and Applied Genetics, 92: 92-100.

Indian Horticulture Database (2011). Online All India Area, Production and Productivity statistics database of Pea, National Horticulture Board, Ministry of Agriculture, Government of India, retrieved on September 20, 2013 from http://www.nhb.gov.in

Jaccard, P. (1908). Nouvelles recherches sur la distribution florale. Bulletin of the Society of Vaud Science National, 44: 223-270.

Kumar, S., Tamura, K., Jakobsen, I.B. and Nei, M. (2001). MEGA2: Molecular Evolutionary Genetics Analysis software. Bioinformatics, 17: 1244-1245.

Kwon, S., Brown, A.F., Hu, J., McGee, R., Watt, C., Kisha, T., Timmerman-Vaughan, G., Grusak, M., McPhee, K. E. and Coyne, C.J. (2012). Genetic diversity, population structure and genome-wide marker-trait association analysis emphasizing seed nutrients of the USDA pea (Pisum sativum L.) core collection. Genes and Genomics, 34: 305-320.

Lema-Ruminska, J., Zalewska, M. and Sadoch, Z. (2004). Radiomutants of Chrysanthemum of the lady group: RAPD analysis of the genetic diversity. Plant Breeding, 123: 290-292.

Lima-Brito, J., Carvalho, A., Martin, A., Heslop-Harrison, J.S. and Guedes-Pinto, H. (2006). Morphological, yield, cytological and molecular characterization of a breed wheat $\times$ tritorderm $\mathrm{F} 1$ hybrid. Journal of Genetics, 85: 123-131.

Mahasi, M.J., Wachira, F.N., Pathak, R.S. and Riungu, T.C. (2009). Genetic polymorphism in exotic safflower (Carthamus tinctorious L.) using RAPD markers. Journal of Plant Breeding and Crop Science, 1 (1): 8-12.

Mattagajasingh, I., Mukherjee, A.K. and Das, P. (2006). Genomic relations among 31 species of Mammillaria Haworth (Cactaceae) using random amplified polymorphic DNA. Z Naturforsch C, 61: 583-591.

Mukherjee, A.K., Dey, A., Acharya, L.K., Pallai, S.K. and Panda, P.C. (2013). Studies on genetic diversity in elite varieties of Chrysanthemum using RAPD and ISSR markers. Indian Journal of Biotechnology, 12: 161-169.

Petterson, D.S., Sipsas, S. and Mackintosh, J.B. (1997). The chemical composition and nutritive value of Australian grain legumes $\left(2^{\text {nd }}\right.$ edn.) Grain Research and Development Corporation, Canberra, Australia.

Prevost, A.S. and Wilkinson, M.J. (1999). A new system of comparing PCR primers applied to ISSR fingerprinting of potato cultivars. Theoretical and Applied Genetics, 98: 107-112.

Raghunathachari, P., Khanna, V.K., Singh, U.S. and Singh, N.K. (2000). RAPD analysis of genetic variability in Indian scented rice germplasm (Oryza sativa L.). Current Science, 79 (7): 994998.

Samatadze, T.E., Zelenina, D.A., Shostak, N.G., Volkov, A. A., Popov, K.V., Rachinskaya O.V., Borisov, A.Y., Tihonovich, I.A., Zelenin, A.V. and Muravenko, O.V. (2008). Comparative genome analysis in pea (Pisum sativum L.) Varieties and Lines with chromosomal and 
molecular markers. Russian Journal of Genetics, 44: 1424-1430.

Samec, P. and Našinec, B. (1996). The use of RAPD technique for the identification and classification of Pisum sativum L. genotypes. Euphytica, 89: 229-234.

Samec, P. and Nasinec, V. (1995). Detection of DNA polymorphism among pea cultivars using RAPD technique. Biologia Plantarum, 37: 321-327.

Simioniuc, D., Uptmoor, R., Friedt, W. and Ordon, F. (2002). Genetic diversity and relationships among pea cultivars revealed by RAPDs and AFLPs. Plant Breeding, 121: 429-435.

Taran, B., Zhang, C., Warkentin, T., Tullu, A. and Vandenberg, A. (2005). Genetic diversity among varieties and wild species accessions of pea (Pisum sativum L.) based on molecular markers, and morphological and physiological characters. Genome, 48: 257-272.

Vand dar Maesen, L.I.G. (1990). Pigeon pea: Origin, History evolution and taxonomy, In The Pigeon Pea, Edited by
Nene NL, Hall SD \& Sheila VK (CAB International University Press, Wallingford, Oxon, UK), 15-46.

Williams, J.G.K., Kubelik, A.R., Livak, K.J., Rafalski, J.A. and Tingey, S.V. (1990a). DNA polymorphisms amplified by arbitrary primers are useful as genetic markers. Nucleic Acids Research, 18: 6531-6535.

Williams, J.G.K., Hanafey, M.K., Rafalski, J.A. and Tingey, S.V., (1990b). Genetic analysis using random amplified polymorphic DNA markers. Methods in Enzymology, 1218: 704-740

Yadav, K., Singh, B.D., Srivastava, C.P., Chand, R. and Yadav, A. (2010). Analysis of genetic divergence in pea (Pisum sativum L.) using quantitative traits and RAPD markers. Indian Journal of Genetics, 70 (4): 363-369.

Zong, X., Redden, R.J., Liu, Q., Wang, S., Guan, J., Liu, J., Xu, Y., Liu, X., Gu, J., Yan, L., Ades, P. and Ford, R. (2009). Analysis of a diverse global Pisum sp. collections and comparison to a Chinese local Pisum sativum L. collection with microsatellite markers. Theoretical and 